\title{
Australian endemic pest tephritids: genetic, molecular and microbial tools for improved Sterile Insect Technique
}

\author{
Kathryn A Raphael ${ }^{1 *}$, Deborah CA Shearman ${ }^{1}$, A Stuart Gilchrist', John A Sved ${ }^{1}$, Jennifer L Morrow², \\ William B Sherwin ${ }^{1}$, Markus Riegler ${ }^{2}$, Marianne Frommer ${ }^{1}$
}

\begin{abstract}
Among Australian endemic tephritid fruit flies, the sibling species Bactrocera tryoni and Bactrocera neohumeralis have been serious horticultural pests since the introduction of horticulture in the nineteenth century. More recently, Bactrocera jarvisi has also been declared a pest in northern Australia. After several decades of genetic research there is now a range of classical and molecular genetic tools that can be used to develop improved Sterile Insect Technique (SIT) strains for control of these pests. Four-way crossing strategies have the potential to overcome the problem of inbreeding in mass-reared strains of $B$. tryoni. The ability to produce hybrids between $B$. tryoni and the other two species in the laboratory has proved useful for the development of genetically marked strains. The identification of $Y$-chromosome markers in B. jarvisi means that male and female embryos can be distinguished in any strain that carries a B. jarvisi $Y$ chromosome. This has enabled the study of homologues of the sex-determination genes during development of $B$ jarvisi and $B$. tryoni, which is necessary for the generation of genetic-sexing strains. Germ-line transformation has been established and a draft genome sequence for $B$. tryoni released. Transcriptomes from various species, tissues and developmental stages, to aid in identification of manipulation targets for improving SIT, have been assembled and are in the pipeline. Broad analyses of the microbiome have revealed a metagenome that is highly variable within and across species and defined by the environment. More specific analyses detected Wolbachia at low prevalence in the tropics but absent in temperate regions, suggesting a possible role for this endosymbiont in future control strategies.
\end{abstract}

\section{Introduction}

The family Tephritidae includes some of the most significant pests of horticulture in the world. Among tephritid fruit flies endemic to Australia, the sibling species, Bactrocera tryoni (Queensland fruit fly, Qfly) and Bactrocera neohumeralis (lesser Queensland fruit fly), have both been serious pests since the establishment of horticulture in Australia in the nineteenth century. Both species are polyphagous, infesting a very broad range of cultivated fruits and vegetables [1]. However, B. tryoni is considered the more serious pest because, in contrast to B. neohumeralis, it is highly invasive and has followed the spread of horticulture through eastern Australia [2],

\footnotetext{
* Correspondence: k.raphael@unsw.edu.au

${ }^{1}$ Evolution and Ecology Research Centre, School of Biological, Earth and Environmental Sciences, The University of New South Wales, Sydney, NSW 2052, Australia

Full list of author information is available at the end of the article
}

including into drier and cooler areas beyond its native habitat (Figure 1a). More recently, Bactrocera jarvisi has been declared a pest in northern Australia [3], although this species has a narrower host range [1]. Its distribution largely follows that of its native host, the Cocky apple (Planchonia careya), but within this region it will infest cultivated mango and guava [4] (Figure 1b).

The traditional form of pest control has been the use of insecticidal cover sprays and baits, but there is now a worldwide move to ban many insecticides, so the need for more environmentally acceptable forms of control is clear. The Sterile Insect Technique (SIT) involves the area-wide release of huge numbers of sterile insects to overflood a wild pest population. The mating of sterile males with wild females results in the collapse of the wild population over successive releases [5]. SIT, as an area-wide form of insect control, can in favourable conditions eliminate pest 
(a)
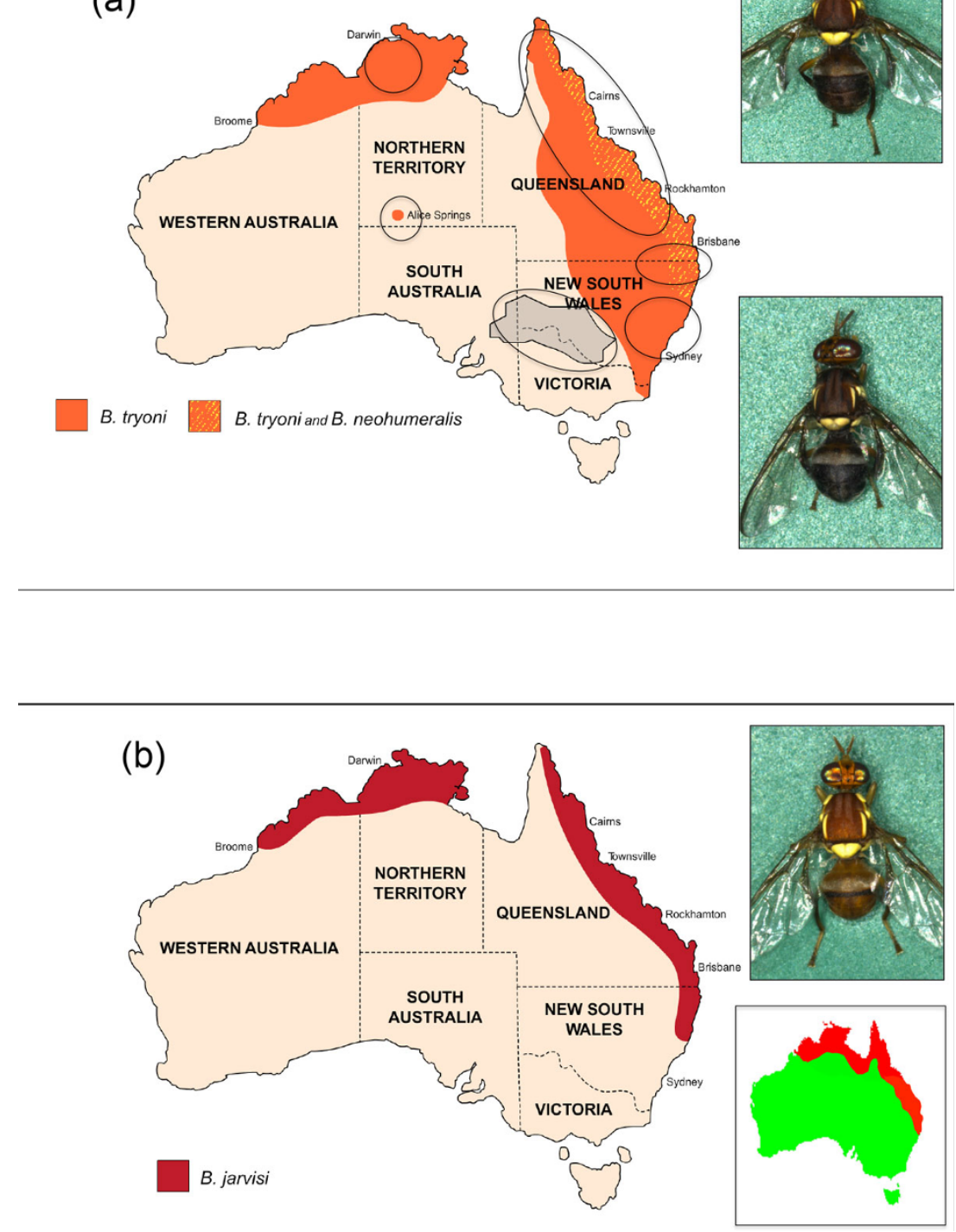

Figure 1 The distributions of $\boldsymbol{B}$. tryoni, $\boldsymbol{B}$. neohumeralis and $\boldsymbol{B}$. jarvisi in Australia. (a) The distribution of $B$. neohumeralis is entirely within the broader distribution of $B$. tryoni. The ovals show the populations of $B$. tryoni that are differentiated by microsatellite analyses. Grey shading is the FFEZ (the Fruit Fly Exclusion Zone). Top right, B. tryoni, bottom right, B. neohumeralis. (b) The distribution of B. jarvisi and, inset, the distribution of its native host the Cocky apple (Planchonia careya). Top right, B. jarvisi.

insects from both horticultural areas and refugia. Additionally, in contrast to insecticides, SIT is species-specific and it is unlikely for insects to become resistant. Disadvantages include the expense and technical difficulties of establishing and maintaining a mass-rearing facility, the need to mark released flies to distinguish them from wild flies in the field, the reduced fitness of mass-reared flies in the field due to laboratory adaptation and the effects of radiation. Amongst Bactrocera, the successful eradication of Bactrocera cucurbitae from the Okinawa islands of
Japan provides a benchmark for SIT programs with mixed sex releases [6].

So far, to control B. tryoni, SIT has been employed at a relatively small scale in Australia, in an area that covers temperate fruit growing regions of the states of New South Wales, Victoria and South Australia, formerly designated the Fruit Fly Exclusion Zone (FFEZ, Figure 1a), and also to control isolated outbreaks in South Australia and Western Australia. These regions have been favourable for SIT as they provide only marginal 
habitat for B. tryoni and, for this reason, outbreaks (as determined by regulatory authorities) are limited in spread and often involve very small numbers of flies [7].

A notable success story for SIT against Qfly is its eradication from Perth, Western Australia in 1995 [8]. Other small-scale field trials in inland regions of eastern Australia could not demonstrate clear reduction of population numbers [9], possibly because of the poor survival of released flies to mating age and natural reduction in the wild population due to the very dry climate of the treatment areas. SIT was used annually within the FFEZ from 1996, however, despite quarantine and control measures, outbreaks of Qfly now occur most years within the zone; from July 2013 Area Freedom was lost from the FFEZ, being retained only in the Greater Sunraysia Pest Free Area, a small FFEZ sub-area of the Murray Valley [10]. The entire state of South Australia is also free of Qfly and has Area Freedom but is vulnerable to outbreaks.

The reasons for loss of Area Freedom in the FFEZ are many, including the risk of migration of flies from surrounding areas, leading to outbreaks within the FFEZ, and the restrictions on the use of insecticides that reduce the ability to control flies in the areas that surround the FFEZ. Climate change may also be contributing to the ability of flies to establish in and adapt to previously marginal habitat [11]. As Dominiak and Ekman [12] point out, the options for fruit fly control are becoming ever more limited with the withdrawal of many pesticides by regulatory authorities, and there is a need for the integration of different control strategies such as Integrated Pest Management or IPM, including aspects of biological control $[13,14]$. SIT is one of the strategies that is easily incorporated into IPM. This review will focus on the use of genetics to improve SIT against endemic Bactrocera pest flies in Australia, including the use of traditional genetic crosses to improve SIT strains, the use of molecular genetic techniques to mark release strains and develop male-only strains, and the new disciplines of genomics, transcriptomics and microbiomics to increase our knowledge of these pest species and inform the development of new control methods.

\section{Improved mass rearing of SIT strains by hybridisation of domesticated strains}

The standardised conditions in a mass-rearing facility are clearly quite different to the variable conditions that wild flies experience in the field, and this results in strong selection as field populations adapt to laboratory conditions. A number of life history traits have been observed to change as a result of domestication including earlier age of reproductive maturity, increased fecundity, more rapid development time, and reduced lifespan and stress resistance. These changes have been reported in B. tryoni
$[9,15]$ as well as other tephritids including medfly, Ceratitis capitata [16], olive fruit fly, Bactrocera oleae [17], and melon fly, Bactrocera cucurbitae [18].

In Qfly, Meats et al. [15] showed that increased productivity occurs rapidly, in the first four generations after domestication, and Gilchrist et al. [20,21] have repeatedly shown that factory strains are inbred. Indeed, Dominiak [19] observed the "self-defeating" nature of ever-increasing production levels that jeopardise fly quality in the Qfly mass rearing facility.

Introducing wild flies into the mass-reared strains every year is ineffective since the mass-reared strain immediately out-competes the wild flies, and simply repeats the problem of inbreeding after domestication. A solution to this problem was proposed by Gilchrist [9] who used a 4-way crossing scheme designed to allow simple and rapid annual replacement of mass-reared strains in even small facilities. The scheme, which involves crossing 3 partially inbred lines with an existing mass-reared strain (Figure 2), avoids the problem of inbreeding and lab adaptation while maintaining high productivity. Because these flies were outbred, their field performance approached that of wild flies, showing improved longevity, temperature stress resistance and dispersal, all important post-release fitness characters that allow released males to compete with wild flies in the field. Significantly, the high productivity shown by these hybrid strains was equal to that of the existing mass-reared strain, meaning that even with annual replacement, the facility will suffer

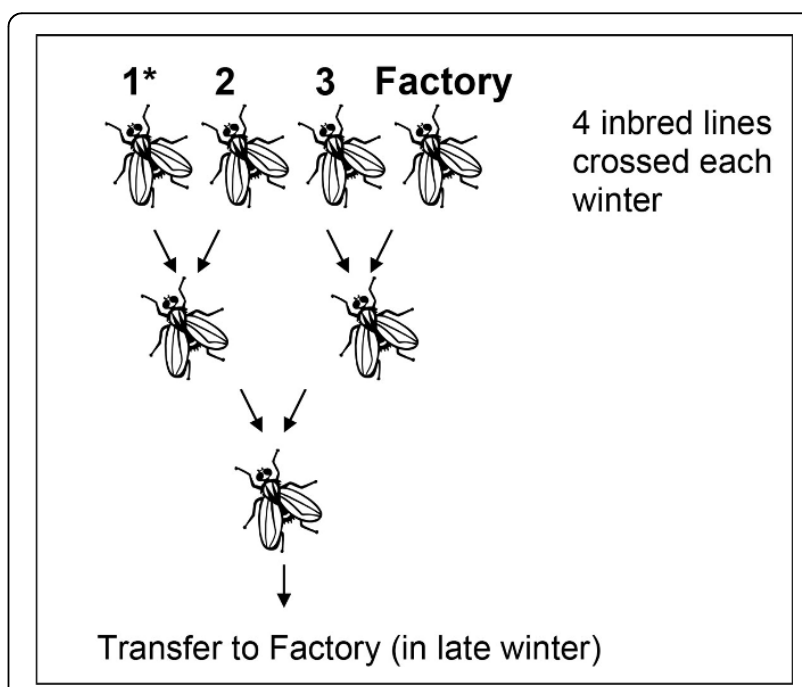

Figure 2 The 4-way crossing scheme to produce an outbred Factory strain [9]. Three domesticated (inbred) strains are maintained in the Factory and crossed following the illustrated scheme with the fourth strain coming from the mass-reared flies. Genetic markers can be incorporated via one of the inbred strains $\left(1^{*}\right)$. If the marker is mitochondrial DNA, then $1^{*}$ must be all female and in the second generation cross the females must be the daughters of the marked females in generation 1 . 
no loss of output [22]. The scheme could be compatible with the incorporation of a genetic-sexing strain (GSS).

\section{Genetically marked strains}

Released flies are normally marked with fluorescent dust in order to distinguish them from wild flies when both are caught in monitoring traps. However a small proportion of sterile flies can escape being marked by this method or they lose the dust after release, and sometimes the dust can be transferred to a wild fly when both are trapped together. This becomes critical where SIT is used in an area that is being monitored for Area Freedom and misidentification of a sterile fly as a wild fly can lead to loss of market access. In addition, the fluorescent dust is considered a hazard for personnel working in the mass-rearing facility, so a more effective and less hazardous marking technique is being sought.

DNA microsatellites have been used to distinguish trapped flies of uncertain origin [20,23-26], but while microsatellites can be useful for identifying released sterile flies, markers that are unique to the released flies are preferable as markers for SIT strains. The ratio of the isotopes ${ }^{13} \mathrm{C}:{ }^{12} \mathrm{C}$ and ${ }^{15} \mathrm{~N}:{ }^{14} \mathrm{~N}$ clearly separates wild and factory flies in both B. tryoni and C. capitata [9,27]. However, this is an expensive technique to employ for day to day monitoring and relies on ready access to specialist personnel and equipment. Below we discuss two newer alternatives: genetic transformation and interspecific or interstrain crosses.

\section{(i) Transformation with molecular markers}

Germ-line transformation is now routine for many nonDrosophilid species and could be used to introduce heritable genetic markers into SIT strains as well as to develop male-only broods. Genetic transformation of B. tryoni has been established [28] using piggyBac as a vector. Flies were marked with the fluorescent proteins EGFP or DsRed under the control of the Drosophila polyubiquitin promoter $[29,30]$, providing the possibility for integrated fluorescent markers. These same vectors have been modified to carry in addition the genes encoding either turboGFP or DsRedExpress markers linked to a C. capitata $\beta 2$-tubulin spermatogenesisspecific promoter (the 1260 and 1261 vectors respectively), as well as an incorporated attP for site-specific integration, and gypsy insulator elements [31], and have been used to successfully mark sperm in C. capitata [31]. When microinjected into B. tryoni eggs, only one of the two vectors was successfully incorporated into the germ-line (Table 1). The flies had green fluorescence in the body and red fluorescence in dissected testes and sperm (Figure 3). The results demonstrated that the C. capitata $\beta 2$-tubulin promoter works successfully in the genus Bactrocera. The fluorescent sperm marking make this a useful strain for sperm transfer studies.

\section{(ii) Markers from interspecific crosses}

An alternative to germ-line transformation for the introduction of genetic markers is to use interspecific or interstrain crosses to incorporate a unique section of a donor DNA into the target SIT strain. Such markers may be useful where regulatory approval for genetically modified organisms is not available or difficult to obtain. Interspecific hybrids between $B$. tryoni and $B$. jarvisi have been used to introduce novel markers into B. tryoni [32]. $B$. tryoni and B. jarvisi have been classified into separate sub-genera of the Bactrocera genus [33]. The two species have distinct morphology and behaviours, including host fruit preference and lure attractancy [4]. DNA evidence [34] has confirmed that there are substantial differences between the species, but not sufficient to merit the different subgeneric status. Cruikshank et al. [35] showed, surprisingly, that the two species can be crossed in the laboratory to produce fertile hybrids. This crossing capacity has provided the ability to produce geneticallymarked strains that could potentially be useful for sterile release, thereby avoiding the necessity for using genetically-transformed strains and allowing rapid incorporation of genetic markers into sterile release strains.

Crossing female B. jarvisi with male B. tryoni, then backcrossing the $\mathrm{F} 1$ and subsequent generations with male B. tryoni produces a strain of Qfly incorporating B. jarvisi mitochondria (Figure 4a) [32]. A simple PCRbased test is available to distinguish the mitochondria of the two species, thereby providing a protocol for distinguishing released flies from wild flies. The mitochondrially-marked B. tryoni stock is robust and fecund, and has been maintained in laboratory cages for 25 generations without evidence of instability. The mitochondrial marker can be incorporated into any desired Qfly strain, including the 4-way hybrids described above (Figure 2), provided that all of the females of one female parental

Table 1 Gene transformation results.

\begin{tabular}{llllll}
\hline Vector number & No. eggs injected & No. G0 adults emerged & \% survival & No. G1 adults screened & No. G1 fluorescent flies \\
\hline 1260 & 896 & 77 & 8.6 & 2974 & 0 \\
1261 & 823 & 55 & 6.7 & 2729 & $2^{*}$ \\
\hline
\end{tabular}

Two vectors, 1260 (pBac\{<af_attP-Ccb2t-tGFP_af<_PUb- DsRed\}) and 1261 (pBac\{>f_attP-Ccb2t-DsRedEx_a>_PUbnlsEGFP\}) [31] were microinjected into B. tryoni eggs with phsp-pBac transposase as helper as in [28].

* from a single G0 male 


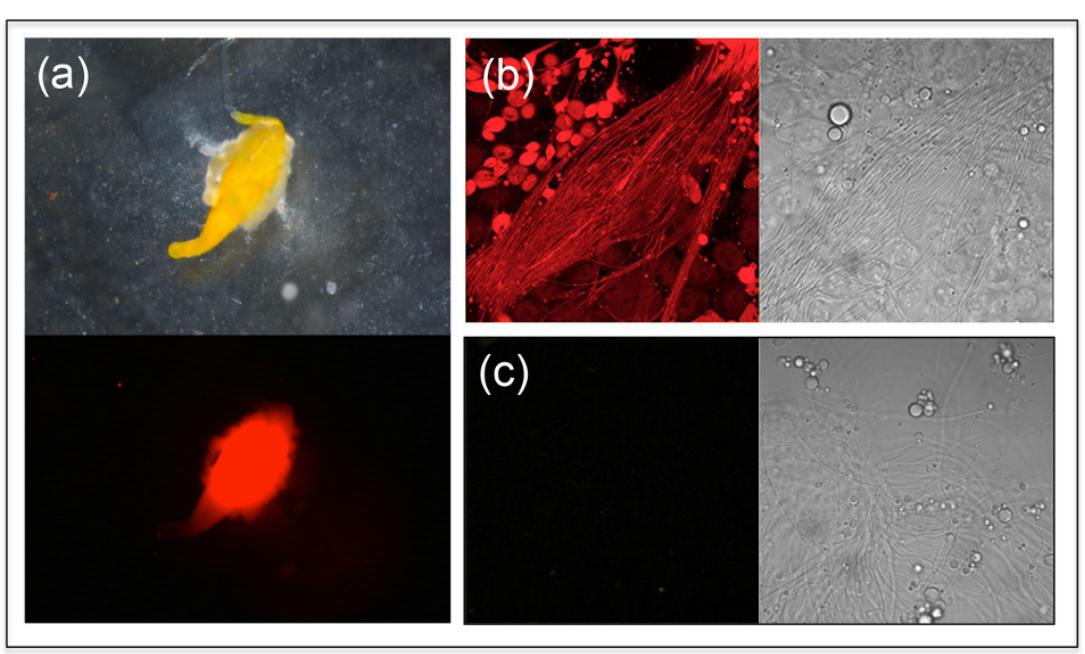

Figure 3 Fluoresence in testes and sperm from B. tryoni transformed with vector 1261. (a) A testis dissected from a 1261 transformed fly. Top, white light; bottom, with dsRED Ultra filter. (b) and (c) Confocal images of sperm from a 1261 transformed male (b) and a non-transformed male (c). Sperm were observed using an inverted Zeiss LSM 5 laser scanning confocal microscope. In each case left is the fluorescence image, the right image is bright field.

strain in the first generation is carrying the B. jarvisi mitochondrion. There is a possibility that stains introgressed in this way may show some incompatibilities with the target species due to the presence of donor mitochondria, and therefore their utility requires testing under factory and field conditions.

From the reciprocal interspecific cross, female $B$. tryoni with male B. jarvisi, it was discovered that part of the $B$. jarvisi mitochondrial cytb and an intronless tra-2 gene were present on the $B$. jarvisi $\mathrm{Y}$ chromosome. This has enabled the establishment of DNA tests for the B. jarvisi Y chromosome [32,36]. The B. jarvisi Y chromosome can be incorporated into the $B$. tryoni autosomal complement by a hybridisation procedure similar to that for the mitochondrial marker, but with $B$. jarvisi used as the male parent (Figure $2 \mathrm{~b}$ ) to achieve a marked $\mathrm{Y}$ chromosome in B. tryoni. For the long-term use of such genetic markers it is, however, crucial that only sterile flies containing the markers are released so that these markers do not become established in field populations.

\section{Genetic sexing strains}

SIT relies on the sterile males of the released strain being able to effectively compete with wild males for wild female mates [37]. In the absence of an efficient method of removing females from the release strain, mixed-sex releases must be used. Careful management of the numbers of mixed-sex release flies, to ensure overflooding of the wild population, is generally sufficient to provide control of the pest species and, in some cases, complete eradication of the invasive species has been achieved. The most outstanding example of the latter is the eradication of screwworm fly, Cochliomyia hominivorax (Coquerel) from the USA and most of Central America [38].

There is evidence in medfly that male-only strains are both more effective and cost efficient than mixed-sex releases. The increased efficiency of male-only releases is brought about by a number of factors: an increase in the number of matings between sterile males and wild females [39,40]; increased dispersal of sterile males in search of mates [40,41]; the elimination of potential damage to fruit caused by sterile stings of released females and consequent bacterial infection [39,42] and the reduction in costs of producing only males if females can be eliminated early in development $[43,44]$. To date, medfly is the only insect where GSSs have been used routinely for control of a pest species [45]. The current mass-reared SIT strains, Vienna-7 and Vienna-8, have been developed over more than 15 years. Both strains are based on Y-linked translocations involving two selectable markers - the primary marker, a fortuitously located temperture-senstive lethal $(t s l)$ mutation and the white pupae $(w p)$ mutation $[44,46]$. Considerable effort and funds from numerous international agencies have been expended on the development and maintenance of the translocation-based genetic sexing strains for medfly. Similar translocation-based strains have been developed and field-tested for Bactrocera cucurbitae $[47,48]$, and Bactrocera dorsalis [24,49]. In Anastrepha ludens translocation-based GSSs have been developed and characterised but field-testing has not yet been reported [50,51]. 


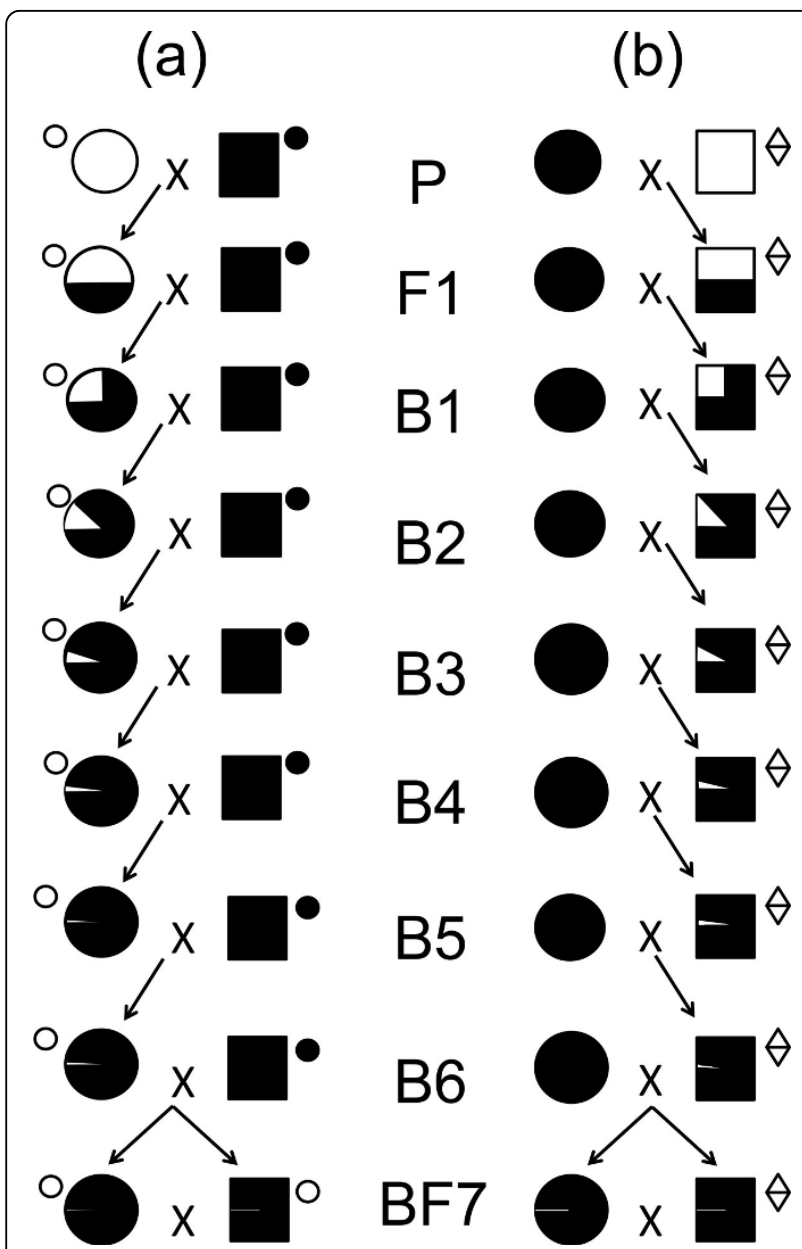

Figure 4 Mating scheme for the transfer of $B$. jarvisi markers into a B. tryoni background. (a) Mating scheme for transfer of B. jarvisi (white) mitochondria into $B$. tryoni (black) background. The mitochondrial type is indicated by small circle (white - B. jarvisi origin; black - B. tryoni origin). (b) Mating scheme for transfer of B. jarvisi (white) Y chromosome into B. tryoni (black) background $P$, parents; $F 1$, first filial generation; $B 1$, backcross generation and number; and BF7, intercross of offspring from backcross generation 6. The proportion of the parental genomic contribution in the hybrids is indicated by the size of the corresponding black and white segments.

It is of interest that in the field trials of the Bactrocera GSS strains, both desirable and undesirable characteristics have been identified in the SIT strains. These include low/adequate egg hatch under mass-rearing conditions [47], lower frequency of mating with wild females [52] and decreased genetic diversity but with comparable mating competitiveness of the sterile males compared to that of wild males [24]. In all of these cases the characteristics seem to be strain-specific suggesting that the selection of the strain for mass-rearing and mating competitiveness may be the most important factor to consider for either male-only or bisexual releases.
To date, the SIT program for Qfly has used mixed-sex releases. An attempt was made to develop a GSS for $B$. tryoni using translocation of visible autosomal mutations to the Y chromosome [57]. Pupal colour markers could not readily be identified because of the great variability of pupal pigmentation, which was refractory to selection. However, other markers are available, such as the chromosome 2 markers white marks and bent wings [58]. Four Y-chromosome translocations with chromosome 2 were obtained using irradiation. These were initially recovered using the chromosome 2 marker white marks. The translocations were then placed over the chromosome 2 marker bent wings, which is lethal at high temperature $\left(31^{\circ} \mathrm{C}\right)$ at the pupal stage. Unfortunately inexplicable sterility effects involving each of the four translocations made the strains unsuitable for development as male-only release strains [57].

Fruit flies of the genus Bactrocera are the most important pests of horticulture in the Asia-Pacific region. The expectation is that GSSs will contribute to optimal SIT control, at the very least for reasons of cost-effectiveness and factory efficiency. However, dispersal behaviour of pests in the genus Bactrocera may be substantially different to that of medfly. For example, a number of studies indicate that newly-emerged B. tryoni males and females disperse further and more rapidly from a release point than does $C$. capitata (typically a kilmometre compared to about 400m; [53-56]). This means that we cannot make $a$ priori assumptions about the extent of improvement from eliminating matings between sterile males and females or from increased dispersal of sterile males in the absence of concommitantly released females. It becomes critical, therefore, that more genetic-sexing strains are developed for the Bactrocera and are rigourously tested in field conditions. It may be that release protocols and field preformance indicators will be even more important in the Bactrocera than in Ceratitis for both mixed-sex and genetic-sexing strains.

\section{Isolation and application of sex-determination genes for development of genetic-sexing strains}

Considerable effort is now being invested in producing male-only strains for many pest species using sophisticated molecular genetic techniques [59]. Sex-determination genes or genes with sex-specific expression have been the main targets for the design of transgene constructs which show sex-specific expression in a number of tephritid pest species such as Anastrepha suspensa [60], B. dorsalis [61] and C. capitata [62]. The ultimate aim is to develop transgenic sexing strains (TSS) in which the transgene acts early in development to eliminate females from the brood.

The bifunctional doublesex $(d s x)$ gene is one of the terminal genes in the somatic sex determination pathway of the model dipteran insect, $D$. melanogaster 
(reviewed in [63]). The female-specific splicing of $d s x$ is regulated through transformer-2 (tra-2) protein, which together with the female-specific transformer (tra) protein forms part of a multi-component spliceosome [64]. It is the non sex-specific TRA-2, which binds to the 13nucleotide repeat elements $(d s x \mathrm{RE})$ in the 3' untranslated region of exon 4 of $d s x[64,65]$, together with the sex-specific TRA $^{\mathrm{F}}$ which ensures the $\mathrm{DSX}^{\mathrm{F}}$ isoform is produced. The sex-specific splicing of tra pre-mRNA is controlled by the key gene, Sexlethal $(S x l)$ (reviewed in [63]). In the presence of two X chromosomes $S x l$ is set in the female-specific mode which, once established, remains in a positive autoregulatory splicing loop from stage 4 in embryonic development [66]

The primary signal of the sex determination pathway in tephritids, unlike that of $D$. melanogaster, is not the number of $\mathrm{X}$ chromosomes, but rather the elusive dominant male determiner, $M$, which is carried on the $\mathrm{Y}$ chromosome [67]. Whereas the primary signal differs, the terminal portion of the sex-determination pathway in dipteran insects other than Drosophila is conserved and was first shown in $B$. tryoni. Isolation of the $d s x$ gene $(B t d s x)$ and examination of its sex-specific transcripts also pointed to the existence of both tra and tra2 homologues in this species [68]. The existence of tra in a tephritid species was first shown in $C$. capitata (Cctra) [69]. The pre-mRNA transcripts of Cctra contain TRA/TRA-2 binding sites in a region of the tra gene covering male-specific exons and their interspersed introns [69]. In contrast to $d s x$, the binding of TRA and TRA-2 to the tra pre-mRNA acts to block strong canonical splice sites, leading to the use of the weak femalespecific splice sites and the removal of the strong splice sites and associated exons to yield the female-specific mRNA. Translation of the female-specific transcript encodes a longer protein product, allowing an autoregulated supply of female-specific tra mRNA and TRA$\mathrm{F}$ protein to be maintained in cells. Conversely, malespecific tra transcripts incorporate stop codons early, leading to production of a truncated and theoretically non-functional protein. Homologues of tra have been also been isolated from B. oleae [70] and Anastrepha species [71] and both B. tryoni and B. jarvisi [36].

Elimination of either tra or tra-2 by RNAi early in development disrupts the mechanism favouring femalespecific splicing of tra and $d s x$ in C. capitata, B. oleae and Anastrepha spp. [69,70,72-74] and leads to the expression of $d s x^{\mathrm{M}}$ and the consequent development of male somatic tissue [75]. Preliminary assessment of tra and tra-2 in B. tryoni (Bttra and Bttra-2) suggests the same functionality. Injection of full-length Bttra-2 and partial Bttra dsRNA fragments into B. tryoni embryos of $3 \mathrm{~h}$ and $7 \mathrm{~h}$ AEL was performed (Figure 5), with seven intersexes recovered from Bttra-2 injections into $7 \mathrm{~h}$ embryos suggesting incomplete phenotypic conversion. Complete conversion resulted from Bttra injections of 3h embryos, whereby two phenotypic males developed that sired all female offspring when mated to a normal female (Figure 5). Thus, either gene can independently induce sex reversal and both genes may also be useful targets for transgenic RNAi in this species. Concommitant injections of buffer showed only marginally higher pupation rates than injections with dsRNA fragments suggesting physical handling was the greatest influence on the resultant numbers of emerged adults.

Other suggested approaches have exploited tetracycline-repressible expression systems to over-express toxic or pro-apoptotic products [76,77]. An improved protocol, termed the Tet-off transgenic embryonic sexing system (TESS; [78]), tested in A. suspensa (Diptera: Tephritidae), utilised a genetic construct that may be applicable across a broad range of species, including Bactrocera species, if species-specific promoters are found and included in the transgene.

The Y-located marker in B. jarvisi has now been used to separate male and female embryos with both the $B$. jarvisi and the $B$. tryoni autosome set, enabling the analysis of sex-specific changes in gene expression at early stages of development [36]. Quantitative PCR pinpointed important differences in transcript abundance between the sexes over time for some sex-determination genes, including tra and $d s x$. These differences in transcript abundance, and the stability of tra-2 expression in male and female

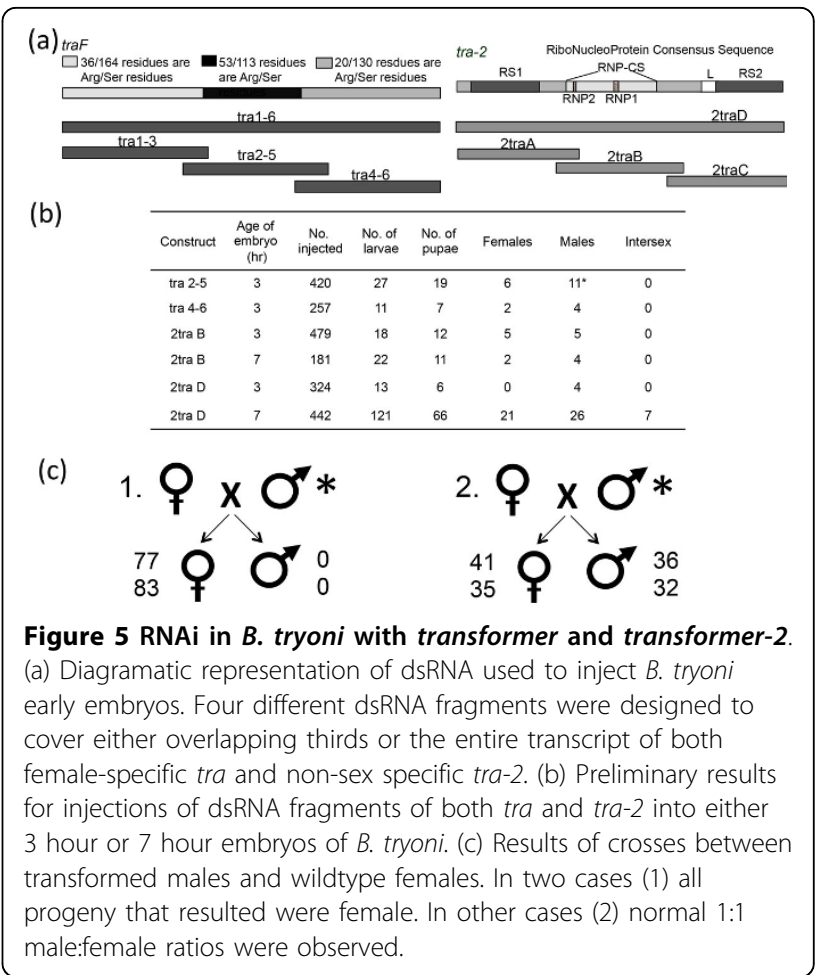


embryos over early development, suggested that $M$ acts on the components of the spliceosome to simultaneously reduce both $\operatorname{tra}^{F}$ and $d s x^{F}$ [36]. Combined with timing of early zygotic transcription of the important Drosophila sex-determination gene, $S x l$, and the cellularisation gene slow as molasses (slam), the developmental period when $M$ is active was estimated as three to six hours after egglaying in $B$. jarvisi and from three hours up to possibly eight hours in B. tryoni [36].

The broad applicability of the piggyBac-based vector systems and the variety of cleverly designed constructs that have been shown to be functional in tephritid pest species [79] mean that the development of TSS strains for $B$. tryoni, using transgene constructs designed around the highly conserved sex-determination genes, tra and tra-2, is therefore feasible in the near future. The release of any transgenic SIT strains in Australia would, however, be subject to approval by the regulatory body.

\section{Genome and transcriptome analyses}

The control of pest insects increasingly requires a detailed knowledge of the genome and transcriptomes; for example, the development of new genetic-sexing strains using molecular techniques requires an understanding of the sex-determination pathway, and the development of new lures requires knowledge of the olfactory system. Microsatellites have been a very important genetic tool for understanding chromosome, pedigree and population structure. The advent of next generation sequencing has opened the door to the study of the genomes and transcriptomes of non-model organisms and is becoming an increasingly important tool for understanding and manipulating pest biology and genetics, and the interactions of these with the environment.

\section{(i) Population structure from microsatellite sequences}

Microsatellite polymorphisms were used to investigate the population structure of B. tryoni [80]. It was found that populations are homogeneous over large distances in north-eastern areas of Australia (Queensland), the likely ancestral home of the species. Further south (New South Wales), and to the west (Northern Territory, Western Australia), endemic populations, probably of more recent origin, were found to differ in composition from the main northern population in Queensland (Figure 1a). Smaller outbreak populations in the FFEZ and surrounding areas were found to be more closely related to the southern populations in New South Wales and to each other than to the main Queensland population $[25,81,82]$ (Figure 1a). These results are able to inform control programs, indicating that eradicating outbreaks and their adjacent populations by exhaustive SIT would be a viable option in southern fruit-growing regions, as well as the isolated populations around Alice Springs in the Northern Territory [80].

More recently, similar findings, using microsatellite analysis, have been made for the Oriental fruit fly. $B$. dorsalis is a species with similar invasiveness to B. tryoni, and with similarly high population numbers and a broad distribution throughout Asia. Microsatellite analyses, albeit on smaller sample sizes, show a pattern of a large, homogeneous population in S.E. Asia with differentiated populations in more geographically isolated regions [83].

Microsatellite analyses have also been used to clarify the species status of pest fruit flies in northern Australia. B. aquilonis was formerly described as a separate species, with low pest status, within the tryoni complex, along with $B$. tryoni and B. neohumeralis [33]. It has been shown that tryoni complex flies in the north-west of Australia cannot be separated genetically from each other, regardless of minor differences in morphology, a result with important quarantine and control implications [84].

\section{(ii) Next Generation total genomes and transcriptomes}

Early B. tryoni genome analysis involved cloning and sequencing of genomic regions based on similarity with Drosophila genes, analysis of complete and degraded mariner elements, and isolation of sequences containing microsatellites, reviewed in Raphael et al. [85]. A first draft, of the $B$. tryoni genome sequence has been completed and submitted to DDBJ/EMBL/GenBank (accession number JHQJ00000000, currently version JHQJ01000000). Scaffolds are based on a $80 x$ coverage from paired-end and mate-pair Illumina sequencing, giving an N50 value of $69 \mathrm{~kb}$. Further, the genomes of B. neohumeralis and B. jarvisi have been sequenced and, although less complete, have been assembled de novo into contigs from paired-end Illumina sequencing (Gilchrist submitted). Assembled transcriptomes of various developmental stages from these three Bactocera species aided the creation of gene models. Continuing assembly of these genomes will be facilitated by the availablity of polytene chromosome and genetic maps for B. tryoni $[58,86]$. The genome sequences of these three related species can form the basis for resequencing comparisons of evolutionary changes, including functional modifications relating to pest status and sex determination. So far, C. capitata is the only other tephritid for which an assembled genome is available.

Despite the relative ease of obtaining transcriptomes, compared to complete genomes, there are relatively few published transcriptomes for tephritid species from next generation sequencing. Transcriptomes have been reported comparing wild and mass-reared medfly [87], adults and different developmental stages of $B$. dorsalis $[88,89]$, pooled life stages of B. oleae [90] and sexed preblastoderm embryos of B. jarvisi [91]. Kumaran et al. 
[92] performed a RNA-seq analysis comparing male $B$. tryoni fed the phytochemical lure zingerone with those not exposed to zingerone. They found enrichment in gene pathways involved in energy metabolism in zingerone fed flies, as well as up-regulation of some transcripts involved in courtship and mating, which agrees with the known effects of zingerone in increasing energy metabolism and improving male competitiveness.

\section{Microbiomes}

Microbial symbionts of tephritid fruit flies have been investigated in a number of tephritid species, and may also be exploitable for the control of pest species (reviewed in [93]). In general, symbiotic microorganisms are an important part of insect biology. Microbial symbionts, either obligate or facultative, can play a role in nutrition, reproduction, immune defense, toxin degradation and behaviour [94]. Evidence for functional roles of specific symbionts in tephritid fruit flies is scarce. Olive fly $B$. oleae is, so far, the only species in which a candidate for an obligate symbiont, "Candidatus Erwinia dacicola" has been identified $[95,96]$, although this bacterium was not detected in laboratory lines of $B$. oleae [97]. It has previously been discussed that $B$. tryoni may benefit from microbial nitrogen fixation [98], while $C$. capitata appears to gain from bacteria in nitrogen fixing and pectinolase functionality [99]. However, for both species, there is no evidence for any obligate microbial symbionts. In contrast to frugivorous tephritids, closely related species within the flower head inhabiting Tephritinae subfamiliy harbor bacterial strains of "Candidatus Stammerula tephritidis" as co-evolved symbionts [100].

Culture dependent and independent analyses of tephritid microbiomes, including of B. tryoni identified variability in microbiome composition, with an overall consistent dominance of few bacterial families [101-103], primarily Enterobacteriaceae, a diverse group with members performing functions including nutrient provisioning $[98,99,104]$.

The transmission efficiency of microbial symbionts between host individuals and generations is a key parameter defining symbiosis, and tephritids possess morphological adaptations that ensure the transmission of microbes to the next generation [105]. Many tephritid fruit flies possess an oesophageal bulb (or diverticulum), which in B. oleae almost exclusively harbours "Candidatus E. dacicola" $[95,96]$. Maternal transmission can be facilitated through smearing of the egg during oviposition $[96,106]$. Decaying fruit also plays a role in transmission of bacteria to fruit fly offspring and as a source of suitable nourishment to developing larvae [107,108].

The applied motivations for studying tephritid microbiomes so far have included the development of bacterial attractants for lure-and-kill or baiting strategies [108-113]; deprivation of beneficial bacteria that provide nutrition or breakdown insecticides [114] leading to decreased fitness in the wild; or conversely supplementation of beneficial bacteria to improve fitness of laboratory and field-release strains [115]. Poor fitness of laboratory lines, following laboratory adaptation [21] may also be an effect of microbial streamlining found in laboratory-reared insects [116], and reduced fitness subsequent to irradiation treatment $[117,118]$ may derive in part from distortion of the microbial diversity [119].

A facultative symbiont worth noting is the maternally inherited intracellular Wolbachia (Alphaproteobacteria). Wolbachia is well known for manipulating host reproduction, commonly by cytoplasmic incompatibility (CI) [120]. In CI, the outcome is crossing sterility between infected males with females that are either uninfected or infected with a different, incompatible strain of Wolbachia. A male-only Wolbachia infected fly line may be released for population control, and this was first field tested as incompatible insect technique (IIT) for naturally infected Rhagoletis cerasi (reviewed in [121]), as an alternative to radiation-based SIT. IIT has been further developed, e.g. through the successful transfer of nonnative Wolbachia strains into uninfected medfly and olive fly, and resulted in population suppression in cage experiments [122-124]. IIT requires male-only releases or an effective way of sterilising released females in order to avoid the establishment of the released Wolbachia strain in the field. A way to overcome this issue could be the combination of IIT with SIT, also with a more favourable lower radiation dose that may have reduced fitness costs [5,125]. Release of Wolbachiainfected low dose irradiated males would provide CI with field females while released infected females would be impaired in fertility due to low dose radiation. As an additional advantage, released flies carry detectable Wolbachia without the need to be further marked.

Research towards applications in B. tryoni has shown that this species harbours Wolbachia infections at very low prevalence in tropical northern Queensland while populations from temperate regions are uninfected [126]. Strikingly, within the tropics, B. tryoni shares identical Wolbachia with five Bactrocera species (including B. neohumeralis) and Dacus axanus [126]. This tropical restriction of Wolbachia in Australian tephritid fruit flies is unusual and warrants further investigation, particularly as the role of Wolbachia in Australian tephritids is still unclear. It is likely that frequent ecological interactions of tropical Australian fruit flies (e.g. in shared host fruits or through parasitoid wasps) results in frequent exposure of tephritid species to Wolbachia resulting in horizontal Wolbachia transmission [126]. 


\section{Conclusions}

A range of genetic tools is now available for B. tryoni that will inform the development of improved SIT strains. This is particularly relevant with the recent announcement of investment in a new SIT facility and research to develop a male-only strain. Performing 4-way crosses would be a relatively straightforward way, requiring few resources, to develop a more robust massrearing strain, overcoming problems of inbreeding, and can be applied to any species. Genetic markers for identification of sterile from wild flies can be introduced into mass-reared strains via the 4-way hybrid method. These markers can include the mitochondrion or $\mathrm{Y}$ chromosome from a related species, Wolbachia or genetic material introduced by germ-line transformation. Some of the genes of the sex-determination pathway have now been isolated and expression data obtained which, together with the availability of germ-line transformation, opens the way for genetic manipulation to produce male-only broods. Ultimately, genetic modification for male-only strains could be introduced into optimal 4-way hybrid strains. Release of the first draft of the genome assembly and imminent publication of further transcriptomes means that important gene families will now be characterised such as genes controlling odorant perception and processing, sex-determination and immune response. The ability to combine expression information from transcriptomes and genome sequence information will enable the identification of gene promoter regions e.g. embryo-specific enhancers for the manipulation of expression of sex-determination genes are an important tool for the generation of TSS. Importantly the genomes of related pest species are also available, albeit at lower coverage at this stage, so that comparisons and genetic experiments between the species will identify the genetic bases of differences in pest status, mating behavior, odorant perception etc. Much still needs to be learned about how the microbiome in B. tryoni is shaped and how it affects fly fitness. High throughput characterisation of the microbiome of flies from different environments in combination with fitness studies will lead to the identification of beneficial microbial isolates that may be used to improve rearing and release programs. Future studies will need to further investigate the unusual distribution of Wolbachia in Australian tephritids, and laboratory experiments are needed to test the role and applicability of this promising bacterium in manipulating reproduction and fitness.

\section{List of abbreviations used}

FFEZ: Fruit Fly Exclusion Zone; GSS: Genetic sexing strain; ITT: Incompatible insect technique; PCR: Polymerase Chain Reaction; Qfly: Queensland fruit fly; SIT: Sterile Insect Technique; TESS: Tet-off transgenic embryonic sexing system; TSS: Transgenic sexing strains.

\section{Competing interests}

All authors declare that they have no competing interests

\section{Acknowledgements}

We thank Marc Schetelig and Ernst Wimmer for the 1260 and 1261 plasmids for research use. KAR acknowledges support from the Australia Pacific Science Foundation. MF acknowledges support from an Australian Research Council Discovery Grant; ASG for support from Horticulture Australia. JLM was supported by an Australian Postgraduate Award scholarship and a FG Swain Award from the Hawkesbury Foundation; MR by funds from the Hawkesbury Institute for the Environment. We gratefully acknowledge the long-standing and continuing contribution of Alfie Meats to research on Qfly.

This article has been published as part of BMC Genetics Volume 15 Supplement 2, 2014: Development and evaluation of improved strains of insect pests for SIT. The full contents of the supplement are available online at http://www.biomedcentral.com/bmcgenet/supplements/15/S2.

Publication of this supplement was funded by the International Atomic Energy Agency. The peer review process for articles published in this supplement was overseen by the Supplement Editors in accordance with BioMed Central's peer review guidelines for supplements. The Supplement Editors declare that they have no competing interests.

\section{Authors' details}

${ }^{1}$ Evolution and Ecology Research Centre, School of Biological, Earth and Environmental Sciences, The University of New South Wales, Sydney, NSW 2052, Australia. ${ }^{2}$ Hawkesbury Institute for the Environment, University of Western Sydney, Locked Bag 1797, Penrith, NSW 2751, Australia.

\section{Published: 1 December 2014}

\section{References}

1. Hancock DL, Hamacek EL, Lloyd AC, Elson-Harris MM: The distribution and host plants of fruit flies (Diptera: Tephritidae) in Australia. Brisbane, Queensland: Department of Primary Industries, Queensland; 2000.

2. Meats A: The bioclimatic potential of the Queensland fruit fly, Dacus (Bactrocera) tryoni, in Australia. Proc Ecol Soc Aust 1981, 11:151-161.

3. Smith ESC: Fruit flies in the home garden. Agnote 2008, 20: 1-3.

4. Fitt GP: The influence of a shortage of hosts on the specificity of oviposition behaviour in species of Dacus (Diptera, Tephritidae). Physiological Entomology 1986, 11:133-143.

5. Bourtzis K, Robinson AS: Insect pest control using Wolbachia and/or radiation. In Insect Symbiosis. Volume 2. CRC Press;Bourtzis K, Miller TA 2006:225-246.

6. Ito $Y$, Kakinohana $H$, Yamagishi M, Kohama T: Eradication of the Melon Fly Bactrocera cucurbitae from Okinawa Japan by means of the sterile insect technique with special emphasis on the role of basic studies. Journal of Asia-Pacific Entomology 2003, 6(2):119-129.

7. Dominiak BC, Daniels DC, Mapson R: Review of the outbreak threshold for Queensland fruit fly (Bactrocera tryoni Froggatt). Plant Protection Quarterly 2011, 26:141-147.

8. Fisher K: Queensland fruit fly (Bactrocera tryoni): eradication from Western Australia. In Fruit fly pests: a world assessment of their biology and management. CRC Press;McPheron BA, Steck, G.J 1996:

9. Gilchrist AS: Improving SIT technique to control fruit fly for citrus market access. Final Report, Project CT06017 Sydney: Horticulture Australia Limited; 2010, 35.

10. Queensland fruit fly outbreak. [http://www.dpi.nsw.gov.au/responses/qff].

11. Sutherst RW, Collyer BS, Yonow T: The vulnerability of Australian horticulture to the Queensland fruit fly, Bactrocera (Dacus) tryoni, under climate change. Australian Journal of Agricultural Research 2000, 51(4):467-480.

12. Dominiak $\mathrm{BC}$, Ekman $\mathrm{JH}$ : The rise and demise of control options for fruit fly in Australia. Crop Protection 2013, 51:57-67.

13. Spinner JE, Cowling AM, Gurr GM, Jessup AJ, Reynolds OL: Parasitoid fauna of Queensland fruit fly, Bactrocera tryoni Froggatt (Diptera: Tephritidae) in inland New South Wales, Australia and their potential for use in augmentative biological control. Australian Journal of Entomology 2011, 50:445-452.

14. Langford EA, Nielsen UN, Johnson SN, Riegler M: Susceptibility of Queensland fruit fly, Bactrocera tryoni (Froggatt) (Diptera: Tephritidae), to entomopathogenic nematodes. Biological Control 2014, 69:34-39. 
15. Meats A, Holmes HM, Kelly GL: Laboratory adaptation of Bactrocera tryoni (Diptera: Tephritidae) decreases mating age and increases protein consumption and number of eggs produced per milligram of protein. Bulletin of Entomological Research 2004, 94(06):517-524.

16. de Souza HML, Matioli SR, de Souza WN: The adaptation process of Ceratitis capitata to the laboratory analysis of life-history traits. Entomologia Experimentalis et Applicata 1988, 49(3):195-201.

17. Economopoulos AP: Adaptation of the Mediterranean Fruit Fly (Diptera: Tephritidae) to Artificial Rearing. Journal of Economic Entomology 1992, 85(3):6.

18. Koyama J, Kakinohana H, Miyatake T: Eradication of the melon fly, Bactrocera cucurbitae, in japan: Importance of Behavior, Ecology, Genetics, and Evolution. Annual Review of Entomology 2004, 49(1):331-349.

19. Dominiak BC, Sundaralingam S, Jiang L, Jessup AJ, Barchia IM: Production level and life history traits of mass reared Queensland fruit fly Bactrocera tryoni (Froggatt) (Diptera: Tephritidae) during 1999/2002 in Australia. Plant Protection Quarterly 2008, 23(3):131-135.

20. Gilchrist AS, Sved JA, Meats A: Genetic relations between outbreaks of the Queensland fruit fly, Bactrocera tryoni (Froggatt) (Diptera: Tephritidae), in Adelaide in 2000 and 2002. Australian Journal of Entomology 2004, 43:157-163.

21. Gilchrist AS, Cameron EC, Sved JA, Meats AW: Genetic Consequences of Domestication and Mass Rearing of Pest Fruit Fly Bactrocera tryoni (Diptera: Tephritidae). Journal of Economic Entomology 2012, 105(3):1051-1056.

22. Gilchrist AS, Meats AW: An evaluation of outcrossing to improve massreared strains of the Queensland fruit fly Bactrocera tryoni. International Journal of Tropical Insect Science 2014, 1-10.

23. Gilchrist AS, Meats A: The genetic structure of populations of an invading species of fruit fly, Bactrocera tryoni, at the species climatic range limit. Heredity 2010, 105:166-172.

24. Isasawin S, Aketarawong N, Thanaphum S: Characterization and evaluation of microsatellite markers in a strain of the oriental fruit fly, Bactrocera dorsalis (Diptera: Tephritidae), with a genetic sexing character used in sterile insect population control. European Journal of Entomology 2012, 109:331-338.

25. Sved JA, Yu H, Dominiak B, Gilchrist AS: Inferring modes of colonization for pest species using heterozygosity comparisons and a shared-allele test. Genetics 2003, 163(2):823-831.

26. Aketarawong N, Chinvinijkul S, Orankanok W, Guglielmino CR, Franz G, Malacrida AR, Thanaphum S: The utility of microsatellite DNA markers for the evaluation of area-wide integrated pest management using SIT for the fruit fly, Bactrocera dorsalis (Hendel), control programs in Thailand. Genetica 2011, 139(1):129-140.

27. Hood-Nowotny RL, Mayr A, Islam A, Robinson AS, Caceres C: Routine isotope marking for the Mediterranean fruit fly (Diptera: Tephritidae). Journal of Economic Entomology 2009, 102:941-947.

28. Raphael KA, Shearman DCA, Streamer K, Morrow JL, Handler AM, Frommer M: Germ-line transformation of the Queensland fruit fly, Bactrocera tryoni, using a piggyBac vector in the presence of endogenous piggyBac elements. Genetica 2011, 139(1):91-97.

29. Handler AM, Harrell RA: Transformation of the Caribbean fruit fly, Anastrepha suspensa, with a piggyBac vector marked with polyubiquitinregulated GFP. Insect Biochemistry and Molecular Biology 2001, 31:199-205.

30. Handler AM, Harrell RA: Polyubiquitin-regulated DsRed marker for transgenic insects. Biotechniques 2001, 31:821-828.

31. Scolari F, Schetelig MF, Bertin S, Malacrida AR, Gasperi G, Wimmer EA: Fluorescent sperm marking to improve the fight against the pest insect Ceratitis capitata (Wiedemann; Diptera: Tephritidae). New Biotechnology 2008, 25(1):76-84.

32. Shearman DCA, Frommer M, Morrow JL, Raphael KA, Gilchrist AS: Interspecific hybridization as a source of novel genetic markers for the sterile insect technique in Bactrocera tryoni (Diptera: Tephritidae). Journal of Economic Entomology 2010, 103(4):1071-1079.

33. Drew RAl: The Tropical Fruit Flies (Diptera: Tephritidae: Dacinae) of the Australasian and Oceanian regions. Memoirs of the Queensland Museum 1989, 26:1-521.

34. Morrow J, Scott L, Congdon B, Yeates D, Frommer M, Sved J: Close genetic similarity between two sympatric species of tephritid fruit ßy reproductively isolated by mating time. Evolution 2000, 54:899-910.

35. Cruickshank L, Jessup AJ, Cruickshank DJ: Interspecipc crosses of Bactrocera tryoni (Frogatt) and Bactrocera jarvisi (Tryon) (Diptera:
Tephritidae) in the laboratory. Australian Journal of Entomology 2001, 40:278-280.

36. Morrow JL, Riegler M, Frommer M, Shearman DCA: Expression patterns of sex-determination genes in single male and female embryos of the two Bactrocera fruit fly species during early development. Insect Molecular Biology 2014, doi: 10.1111/imb.12123.

37. Knipling EF: Possibilities of insect control or eradication through the use of sexually sterile males. Journal of Economic Entomology 1955, 48(4):459-462.

38. Krafsur ES: Sterile insect technique for suppressing and eradicating insect population: 55 years and counting. Journal of Agricultural Entomology 1998, 15:303-317.

39. Mclnnis DO, Tam S, Grace C, Miyashita D: Population suppression and sterility rates induced by variable sex ratio sterile insect releases of Ceratitis capitata (Diptera:Tephritidae) in Hawaii. Annals of the Entomological Society of America 1994, 87(2):231-240.

40. Rendon P, Mclnnis D, Lance D, Stewart J: Medfly (Diptera : Tephritidae) genetic sexing: Large-scale field comparison of males-only and bisexual sterile fly releases in Guatemala. Journal of Economic Entomology 2004, 97(5):1547-1553.

41. Hendrichs J, Franz G, Rendón P: Increased effectiveness and applicability of the sterile insect technique through male-only releases for control of Mediterranean fruit flies during fruiting seasons. Journal of Applied Entomology 1995, 119:371-377.

42. Cayol JP, Causse R, Louis C, Barthes J: Medfly Ceratitis capitata (Wiedemann (Dipt Trypetidae) as a rot vector in laboratory conditions. Journal of Applied Entomology 1994, 117:338-343.

43. Caceres $C$ : Mass rearing of temperature sensitive genetic sexing strains in the Mediterranean fruit fly (Ceratitis capitata). Genetica 2002, 116(1):107-116.

44. Robinson AS: Genetic sexing strains in medfly, Ceratitis capitata, sterile insect technique programmes. Genetica 2002, 116(1):5-13.

45. Franz $G$, Kerremans $P$, Rendon P, Hendrichs J: Development and application of genetic sexing systems based for the Mediterranean fruit fly based on a temperature sensitive lethal. In Fruit Fly Pests A World Assessment of Their Biology and Management. St Lucie Press;McPheron BA, Steck GJ 1996:185-196.

46. Robinson AS, Franz G, Fisher K: Genetic sexing strains in the medfly Ceratitis capitata: development mass rearing and field application. Trends in Entomology 1999, 2:81-104.

47. McInnis DO, Tam S, Lim R, Komatsu J, Kurashima R, Albrecht C: Development of a Pupal Color-Based Genetic Sexing Strain of the Melon Fly, Bactrocera cucurbitae (Coquillett) (Diptera: Tephritidae). Annals of the Entomological Society of America 2004, 97(5):1026-1033.

48. Mclnnis DO, Leblanc L, Mau R: Melon fly (Diptera: Tephritidae) genetic sexing: all-malesterile fly releases in Hawaii. Proceedings of the Hawaiian Entomology Society 2007, 39:105-110.

49. McCombs SD, Saul SH: Translocation-based geneticsexing system for the Oriental Fruit Fly (Diptera: Tephritidae)based on pupal color dimorphism. Annals of the Entomological Society of America 1995, 88(5):695-698.

50. Orozco D, Meza JS, Zepeda S, Solís E, Quintero-Fong JL: Tapachula-7, a new genetic sexing strain of the Mexican fruit fly (Diptera: Tephritidae): sexual compatibility and competitiveness. Journal of Economic Entomology 2013, 106(2):735-741.

51. Zepeda-Cisneros CS, Hernández JSM, García-Martínez V, Ibañez-Palacios J, Zacharopoulou A, Franz G: Development, genetic and cytogenetic analyses of genetic sexing strains of the Mexican fruit fly Anastrepha ludens Loew (Diptera: Tephritidae). BMC Genetics 15(Suppl 2):S1.

52. Haq IU, Vreysen MJB, Abd-Alla A, Hendrichs J: Ability of genetic sexing strain male melon flies (Diptera: Tephritidae) to suppress wild female remating: implications for SIT. Florida Entomologist 2013, 96:839-849.

53. Meats A, Edgerton JE: Short- and long-range dispersal of the Queensland fruit fly, Bactrocera tryoni and its relevance to invasive potential, sterile insect technique and surveillance trapping. Australian Journal of Experimental Agriculture 2008, 48(9):1237-1245.

54. Gilchrist AS, Meats AW: Factors affecting the dispersal of large-scale releases of the Queensland fruit fly, Bactrocera tryoni. Journal of Applied Entomology 2012, 136(4):252-262.

55. Meats A, Smallridge CJ: Short- and long-range dispersal of medfly, Ceratitis capitata (Dipt., Tephritidae), and its invasive potential. Journal of Applied Entomology 2007, 131(8):518-523. 
56. Meats A, Smallridge CJ, Dominiak BC: Dispersion theory and the sterile insect technique: application to two species of fruit fly. Entomologia Experimentalis et Applicata 2006, 119(3):247-254.

57. Meats $A$, Maheswaran P, Frommer M, Sved J: Towards a male-only release system for SIT with the Queensl and fruit fly, Bactrocera tryoni, using a genetic sexing strain with a temperature-sensitive lethal mutation. Genetica 2002, 116(1):97-106.

58. Zhao JT, Frommer M, Sved J, Gillies CB: Genetic and molecular markers of the Queensland fruit fly Bactrocera tryoni. Journal of Heredity 2003, 94:416-420.

59. Franz G, Robinson AS: Molecular technologies to improve the effectiveness of the sterile insect technique. Genetica 2011, 139(1):1-5.

60. Schetelig MF, Handler AM: A transgenic embryonic sexing system for Anastrepha suspensa (Diptera: Tephritidae). Insect Biochemistry and Molecular Biology 2012, 42(10):790-795.

61. Chen SL, Dai SM, Lu KH, Chang C: Female-specific doublesex dsRNA interrupts yolk protein gene expression and reproductive ability in Oriental fruit fly Bactrocera dorsalis (Hendel). Insect Biochemistry and Molecular Biology 2008, 38:155-165.

62. Ogaugwu CE, Schetelig MF, Wimmer EA: Transgenic sexing system for Ceratitis capitata (Diptera: Tephritidae) based on female-specific embryonic lethality. Insect Biochemistry and Molecular Biology 2013, 43(1):1-8.

63. Verhulst EC, van de Zande L, Beukeboom L: Insect sex determination: it all evolves around transformer. Current Opinion in Genetics \& Development 2010, 20(4):376-383.

64. Lynch KW, Maniatis T: Assembly of specific SR protein complexes on distinct regulatory elements of the Drosophila doublesex splicing enhancer. Genes and Development 1996, 10:2089-2101.

65. Hedley ML, Maniatis T: Sex-specific splicing and polyadenylation of $d s x$ pre-messenger-RNA requires a sequence that binds specifically to tra-2 protein in vitro. Cell 1991, 65(4):579-586.

66. Bell LR, Horabin Jl, Schedl P, Cline TW: Positive autoregulation of Sex-lethal by alternative splicing maintains the female determined state in Drosophila. Cell 1991, 65:229-239.

67. Willhoeft $\mathrm{U}$, Franz $\mathrm{G}$ : Identification of the sex-determining region of the Ceratitis capitata Y chromosome by deletion mapping. Genetics 1996, 144:737-745

68. Shearman DC, Frommer M: The Bactrocera tryoni homologue of the Drosophila melanogaster sex-determination gene doublesex. Insect Molecular Biology 1998, 7:355-366.

69. Pane A, Salvemini M, Delli Bovi P, Polito C, Saccone G: The transformer gene in Ceratitis capitata provides a genetic basis for selecting and remembering the sexual fate. Development 2002, 129(15):3715-3725.

70. Lagos D, Koukidou M, Savakis C, Komitopoulou K: The transformer gene in Bactrocera oleae: the genetic switch that determines its sex fate. Insect Molecular Biology 2007, 16(2):221-230.

71. Ruiz MF, Milano A, Salvemini M, Eirin-Lopez JM, Perondini ALP, Selivon D, Polito C, Saccone G, Sanchez L: The gene transformer of Anastrepha fruit flies (Diptera, Tephritidae) and Its evolution in insects. PloS One 2007, 2(11):e1239.

72. Salvemini M, Robertson M, Aronson B, Atkinson P, Polito LC, Saccone G: Ceratitis capitata transformer-2 gene is required to establish and maintain the autoregulation of Cctra, the master gene for female sex determination. International Journal of Developmental Biology 2009, 53(1):109-120.

73. Sarno F, Ruiz MF, Eirín-Lápez JM, Perondini AL, Selivon D, Sànchez L: The gene transformer-2 of Anastrepha fruit flies (Diptera, Tephritidae) and its evolution in insects. BMC Evolutionary Biology 2010, 10(1):140.

74. Schetelig MF, Milano A, Saccone G, Handler AM: Male only progeny in Anastrepha suspensa by RNAi-induced sex reversion of chromosomal females. Insect Biochemistry and Molecular Biology 2012, 42(1):51-57.

75. Saccone G, Salvemini M, Pane A, Polito LC: Masculinization of XX Drosophila transgenic flies expressing the Ceratitis capitata DoublesexM isoform. International Journal of Developmental Biology 2008, 52(8):1051-1057.

76. Heinrich JC, Scott MJ: A repressible female-specific lethal genetic system for making transgenic insect strains suitable for a sterile-release program. Proceedings of the National Academy of Sciences of the United States of America 2000, 97(15):8229-8232.

77. Thomas DD, Donnelly CA, Wood RJ, Alphey LS: Insect population control using a dominant, repressible, lethal genetic system. Science 2000, 287(5462):2474-2476.
78. Schetelig MF, Handler AM: Strategy for enhanced transgenic strain development for embryonic conditional lethality in Anastrepha suspensa. Proceedings of the National Academy of Science USA 2012, 109:9348-9353.

79. Handler AM, O'Brochta DA: Transposable Elements for Insect Transformation. Insect Molecular Biology and Biochemistry Academic Press; 2012, 90-133.

80. Yu H, Frommer M, Robson MK, Meats AW, Shearman DCA, Sved JA: Microsatellite analysis of the Queensland fruit fly Bactrocera tryoni (Diptera: Tephritidae) indicates spatial structuring: implications for population control. Bulletin of Entomological Research 2001, 91(02):139-147.

81. Gilchrist AS, Meats AW: The genetic structure of populations of an invading pest fruit fly, Bactrocera tryoni, at the species climatic range limit. Heredity 2010, 105(2):165-172.

82. Gilchrist AS, Dominiak B, Gillespie PS, Sved JA: Variation in population structure across the ecological range of the Queensland fruit fly, Bactrocera tryoni. Australian Journal of Zoology 2006, 54(2):87-95.

83. Aketarawong N, Bonizzoni M, Thanaphum S, Gomulski LM, Gasperi G, Malacrida AR, Gugliemino CR: Inferences on the population structure and colonization process of the invasive oriental fruit fly, Bactrocera dorsalis (Hendel). Molecular Ecology 2007, 16(17):3522-3532.

84. Cameron EC, Sved JA, Gilchrist AS: Pest fruit fly (Diptera: Tephritidae) in northwestern Australia: one species or two? Bull Entomol Res 2010, 100(2):197-206.

85. Raphael KA, Whyard S, Shearman DCA, An X, Frommer M: Bactrocera tryoni and closely related pest tephritids-molecular analysis and prospects for transgenic control strategies. Insect Biochemistry and Molecular Biology 2004, 34(2):167-176.

86. Zhao JT, Frommer M, Sved JA, Zacharopoulou A: Mitotic and polytene chromosome analyses in the Queensland fruit fly, Bactrocera tryoni (Diptera : Tephritidae). Genome 1998, 41(4):510-526.

87. Calla B, Hall B, Hou SB, Geib SM: A genomic perspective to assessing quality of mass-reared SIT flies used in Mediterranean fruit fly (Ceratitis capitata) eradication in California. BMC Genomics 2014, 15.

88. Hsu JC, Chien TY, Hu CC, Chen MJ, Wu WJ, Feng HT, Haymer DS, Chen CY: Discovery of genes related to insecticide resistance in Bactrocera dorsalis by functional genomic analysis of a de novo assembled transcriptome. Plos One 2012, 7(8):e40950.

89. Zheng W, Peng T, He W, Zhang H: High-throughput sequencing to reveal genes involved in reproduction and development in Bactrocera dorsalis (Diptera: Tephritidae). PloS One 2012, 7(5):e36463.

90. Pavlidi N, Dermauw W, Rombauts S, Chrisargiris A, Van Leeuwen T, Vontas J: Analysis of the Olive fruit fly transcriptome and phylogenetic classification of the major detoxification gene families. PloS One 2013, 8(6):e66533.

91. Morrow JL, Riegler M, Gilchrist AS, Shearman DCA, Frommer M: Comprehensive transcriptome analysis of early male and female Bactrocera jarvisi embryos. BMC Genetics 2014, 15(Suppl 2):S7.

92. Kumaran N, Prentis PJ, Mangalam KP, Schutze MK, Clarke AR: Sexual selection in true fruit flies (Diptera: Tephritidae): transcriptome and experimental evidences for phytochemicals increasing male competitive ability. Molecular Ecology 2014, doi: 10.1111/mec.12880

93. Lauzon CR: Symbiotic relationships of tephritids. In Insect Symbiosis. Volume 1. CRC Press;Bourtzis K, Miller TA 2003:115-129.

94. Vavre F, Braig HR: Primary symbionts, so similar, yet so different. In Manipulative Tenants Bacteria Associated with Arthropods. CRC Press;ZchoriFein E, Bourtzis K 2012:xvii-xxxvii.

95. Petri L: Untersuchungen uber die Darmbakterien der Olivenfliege. Zentralbl Bakteriol Parasitenkd Infektionskr II 1910, 26:357-367.

96. Capuzzo C, Firrao G, Mazzon L, Squartini A, Girolami V: 'Candidatus Erwinia dacicola', a coevolved symbiotic bacterium of the olive fly Bactrocera oleae (Gmelin). International Journal of Systematic and Evolutionary Microbiology 2005, 55(4):1641-1647.

97. Kounatidis I, Crotti E, Sapountzis P, Sacchi L, Rizzi A, Chouaia B, Bandi C, Alma A, Daffonchio D, Mavragani-Tsipidou P, Bourtzis K: Acetobacter tropicalis is a major symbiont of the olive fruit fly (Bactrocera oleae). Applied and Environmental Microbiology 2009, 75(10):3281-3288.

98. Murphy KM, Teakle DS, MacRae IC: Kinetics of colonization of adult Queensland fruit flies (Bactrocera tryoni) by dinitrogen-fixing alimentary tract bacteria. Applied and Environmental Microbiology 1994, 60(7):2508-2517.

99. Behar A, Yuval B, Jurkevitch E: Enterobacteria-mediated nitrogen fixation in natural populations of the fruit fly Ceratitis capitata. Molecular Ecology 2005, 14(9):2637-2643. 
100. Mazzon L, Piscedda A, Simonato M, Martinez-Sañudo I, Squartini A, Girolami V: Presence of specific symbiotic bacteria in flies of the subfamily Tephritinae (Diptera Tephritidae) and their phylogenetic relationships: proposal of 'Candidatus Stammerula tephritidis'. International Journal of Systematic and Evolutionary Microbiology 2008, 58(6):1277-1287

101. Behar A, Ben-Yosef M, Lauzon CR, Yuval B, Jurkevich E: Structure and function of the bacterial community associated with the Mediterranean fruit fly. In Insect Symbiosis Bourtzis K, Miller TA 2009, 3:251-271.

102. Fitt GP, O'Brien RW: Bacteria associated with four species of Dacus (Diptera: Tephritidae) and their role in the nutrition of the larvae. Oecologia 1985, 67(3):447-454.

103. Thaochan N, Drew RAl, Hughes JM, Vijaysegaran S, Chinajariyawong A Alimentary tract bacteria isolated and identified with API-20E and molecular cloning techniques from Australian tropical fruit flies, Bactrocera cacuminata and B. tryoni. Journal of Insect Science 2010, 10:131.

104. Murphy KM, MacRae IC, Teakle DS: Nitrogenase activity in the Queensland fruit fly, Dacus tryoni. Aust J Biol Sci 1988, 41:447-451.

105. Bateman MA: The ecology of fruit flies. Annual Review of Entomology 1972, 17(1):493-518.

106. Estes AM, Hearn DJ, Bronstein JL, Pierson EA: The olive fly endosymbiont, "Candidatus Erwinia dacicola", switches from an intracellular existence to an extracellular existence during host insect development. Applied and Environmental Microbiology 2009, 75(22):7097-7106.

107. Behar A, Jurkevitch $E$, Yuval B: Bringing back the fruit into fruit fly-bacteria interactions. Molecular Ecology 2008, 17(5):1375-1386.

108. Drew RAl, Lloyd AC: Relationship of fruit flies (Diptera: Tephritidae) and their bacteria to host plants. Annals of the Entomological Society of America 1987, 80(5):629-636.

109. Drew RAI, Courtice AC, Teakle DS: Bacteria as a natural source of food for adult fruit flies (Diptera: Tephritidae). Oecologia 1983, 60(3):279-284.

110. Lauzon C, Sjogren R, Prokopy R: Enzymatic capabilities of bacteria associated with apple maggot flies: a postulated role in attraction. Journal of Chemical Ecology 2000, 26(4):953-967.

111. Prabhakar CS, Sood P, Kanwar SS, Sharma PN, Kumar A, Mehta PK: Isolation and characterization of gut bacteria of fruit fly, Bactrocera tau (Walker). Phytoparasitica 2013, 41:193-201.

112. Thaochan N, Chinajariyawong A: Attraction of Bactrocera cucurbitae and B. papayae (Diptera: Tephritidae) to the Odor of the Bacterium Enterobacter cloacae. The Philippine Agricultural Scientist 2011, 94:(1):83-87.

113. Wang $H$, Jin L, Peng T, Zhang H, Chen Q, Hua Y: Identification of cultivable bacteria in the intestinal tract of Bactrocera dorsalis from three different populations and determination of their attractive potential. Pest Management Science 2013, 70:80-87.

114. Bousch MG, Matsumura F: Insecticidal Degradation by Pseudomonas melophthora, the Bacterial Symbiote of the Apple Maggot. Journal of Economic Entomology 1967, 60(4):918-920.

115. Meats A, Streamer K, Gilchrist AS: Bacteria as food had no effect on fecundity during domestication of the fruit fly, Bactrocera tryoni. Journal of Applied Entomology 2009, 133(8):633-639.

116. Chandler JA, Lang JM, Bhatnagar S, Eisen JA, Kopp A: Bacterial communities of diverse Drosophila species: ecological context of a hostmicrobe model system. PLoS Genetics 2011, 7(9):e1002272.

117. Parker A, Mehta K: Sterile insect technique: A model for dose optimization for improved sterile insect quality. Florida Entomologist 2007, 90(1):88-95

118. Rull J, Encarnacin N, Birke A: Mass rearing history and irradiation affect mating performance of the male fruit fly, Anastrepha obliqua. Journal of Insect Science 2012, 12:45.

119. Ben Ami E, Yuval B, Jurkevitch E: Manipulation of the microbiota of massreared Mediterranean fruit flies Ceratitis capitata (Diptera: Tephritidae) improves sterile male sexual performance. The ISME Journal 2010, 4(1):28-37.

120. Schneider D, Miller WJ, Riegler M: Arthropods shopping for Wolbachia. Manipulative tenants: bacteria associated with arthropods CRC Press, Taylor \& Francis Group; 2012, 149-174.

121. Riegler M, Stauffer C: Wolbachia infections and superinfections in cytoplasmically incompatible populations of the European cherry fruit fly Rhagoletis cerasi (Diptera, Tephritidae). Molecular Ecology 2002, 11(11):2425-2434.
122. Apostolaki A, Livadaras I, Saridaki A, Chrysargyris A, Savakis C, Bourtzis K: Transinfection of the olive fruit fly Bactrocera oleae with Wolbachia: towards a symbiont-based population control strategy. Journal of Applied Entomology 2011, 135(7):546-553.

123. Zabalou S, Apostolaki A, Livadaras I, Franz G, Robinson AS, Savakis C, Bourtzis K: Incompatible insect technique: Incompatible males from a Ceratitis capitata genetic sexing strain. Entomologia Experimentalis et Applicata 2009, 132(3):232-240.

124. Zabalou S, Riegler M, Theodorakopoulou M, Stauffer C, Savakis C, Bourtzis K: Wolbachia-induced cytoplasmic incompatibility as a means for insect pest population control. Proceedings of the National Academy of Sciences of the United States of America 2004, 101(42):15042-15045.

125. Arunchalam N, Curtis CF: Integration of radiation with cytoplasmic incompatibility for genetic control in the Culex pipiens complex (Diptera: Culicidae). Journal of Medical Entomology 1985, 22:648-653.

126. Morrow JL, Frommer M, Shearman DCA, Riegler M: Tropical tephritid fruit fly community with high incidence of shared Wolbachia strains as platform for horizontal transmission of endosymbionts. Environmental Microbiology 2014, doi: 10.1111/1462-2920.12382.

\section{doi:10.1186/1471-2156-15-S2-S9}

Cite this article as: Raphael et al:: Australian endemic pest tephritids: genetic, molecular and microbial tools for improved Sterile Insect Technique. BMC Genetics 2014 15(Suppl 2):S9.

\section{Submit your next manuscript to BioMed Central and take full advantage of:}

- Convenient online submission

- Thorough peer review

- No space constraints or color figure charges

- Immediate publication on acceptance

- Inclusion in PubMed, CAS, Scopus and Google Scholar

- Research which is freely available for redistribution

Submit your manuscript at www.biomedcentral.com/submit
C) Biomed Central 